\title{
Fallopian tube fibroid
}

\section{Keywords: fallopian tube, leiomyoma}

\section{Introduction}

Leiomyomas arise from smooth muscle cells of uterus or vascular walls that supply the uterus. Very rarely the ovary, broad ligament and fallopian tubes can also be involved. Though the uterus and tubes are derived from Mullerian system and both contain smooth muscles, uterine myomas are very common whereas fallopian tube myomas are least frequently encountered. Most cases of fallopian tube leiomyomas are asymptomatic and chance-findings at surgical exposure for other reasons or found only at autopsy.

\section{Case report}

A 41year Para 3 was admitted with colicky pain abdomen with vomiting and features of dehydration. Her cycles were 5-7days/30days with excessive flow accompanied with pain and dyspareunia since 7 months. Her L. M. P. was 7days prior to admission. She was treated with antibiotics for PID in peripheral institutions during this period. All her deliveries were normal with uneventful post-partum period and she underwent minilap tubal ligation 11years back. Her vitals were stable, abdominal examination revealed a tender distended lower abdomen. On pelvic examination a tender ill-defined mass attached to uterus with restricted mobility was felt in the left adnexa. USG reported Left adnexal mass simulating Left Ovarian Cyst (Figure 1). The uterus was normal in size with thin endometrium and the endometrial cavity was empty. The blood picture reveled $\mathrm{Hb}$ count $11 \mathrm{gram} / \mathrm{dl}$, TLC $10,200 / \mathrm{cmm}, \beta$-hcg $6 \mathrm{ng} / \mathrm{ml}$, other tumour markers (CA 125, CEA, AFP, LDH) within normal limits. With provisional diagnosis of Twisted Ovarian tumour (left) or degenerated subserous fibroid, we proceeded with the case. Under G. A. laparoscopy was performed, which showed a mass in the left fallopian tube at the isthmic portion undergone torsion. The uterus, right tube and ovary were normal. After untwisting the mass LAVH with BSO was performed. The specimen clearly showed a left fallopian tube leiomyoma (Figure 2). Post- operative period was uneventful. The histopathology report came out to be LEFT FALLOPIAN TUBE ADENOLEIOMYOMA at its isthmic portion without any features of malignancy.

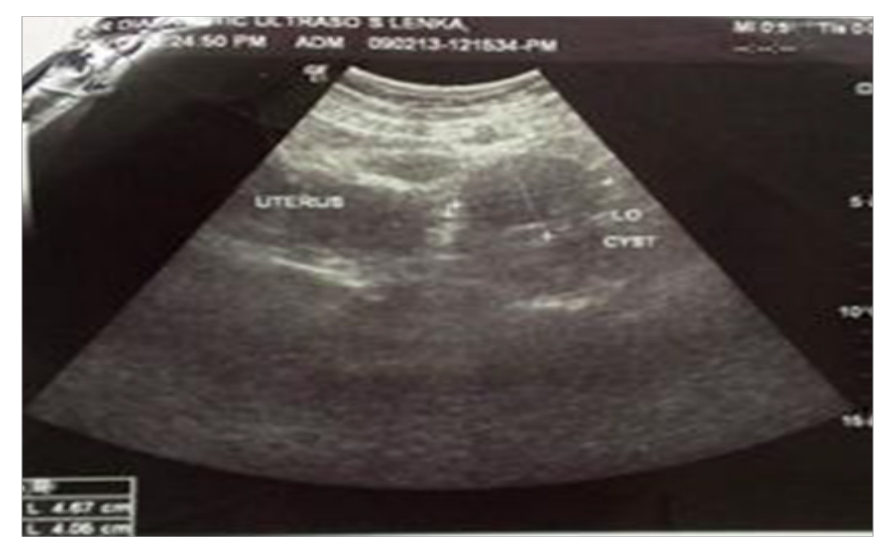

Figure I USG simulating an ovarian cyst.
Volume 5 Issue I - 2017

\section{Ritu Vaibhav Jain \\ Shri Mahaveer Hospital, India}

Correspondence: Ritu Vaibhav Jain, Shri Mahaveer Hospital, B-Building, DANIVILLA, Opp PAHUNA- state guest house, Bhagat singh square, Shankar nagar main road, Civil lines, Raipur, Chandigarh 40200I, India, Email bijaleejain@yahoo.com

Received: April 18, 2017| Published: May 05, 2017

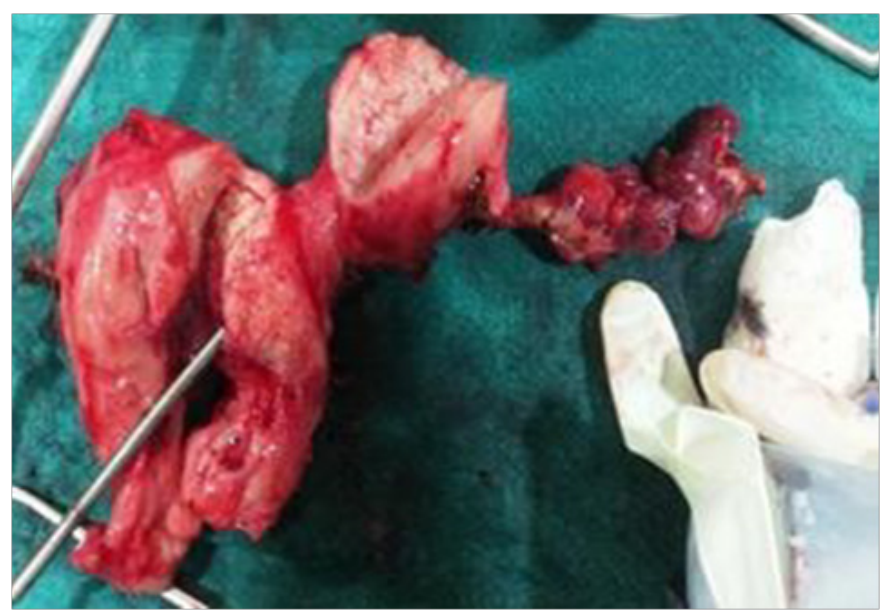

Figure $\mathbf{2}$ Showing left tubal solid growth at its isthmic portion.

\section{Discussion and review of literature}

Leiomyomas of fallopian tube are rare, typically co- incidental findings at autopsy or unrelated surgical procedures. ${ }^{1}$ They are mostly single, small and unilateral but may be of variable size from microscopic to more than $15 \mathrm{~cm}$ large. ${ }^{2}$ They may grow excessively and undergo torsion or degenerations. ${ }^{3}$ They are rarely diagnosed pre-operatively. Powerful USG could be helpful in diagnosing this condition, but laparoscopy can be used for definite diagnosis and management. ${ }^{4}$ Neither CT nor laparoscopy sometimes could specify the tumour where final diagnosis is made by biopsy. ${ }^{5}$ In 2004 for the first time a case could be successfully managed by laparoscopy. ${ }^{6}$

\section{Conclusion}

Asymptomatic fallopian tube leiomyoma being chance-findings are very rare and symptomatic fallopian tube leiomyoma as in this case are still rarer. This condition should be kept in mind as a differential diagnosis of any adnexal mass.

\section{Acknowledgments}

None. 


\section{Conflict of interest}

The author declares no conflict of interest.

\section{References}

1. Misao R, Niwa K, Iwagaki S, et al. Leiomyoma of the fallopian tube. Gynecol obstet invest. 2000;49(4):279-280.

2. Yang CC, Wen KC, Chen P, et al. PH-Primary leiomyoma of fallopian tube-pre-operative ultrasound findings. $J$ chin med Assoc. 2007;70(2):8083.
3. Tarek Bardawil. Fallopian Tube Disorders. Medscape, USA; 2014.

4. Yang CC, Wen KC, Chen P, et al. Primary leiomyoma of the fallopian tube: preoperative ultrasound findings. J Chin Med Assoc. 2007;70(2):80-83.

5. Journal De Gynecologie Obstetrique Et Biologie De La Reproduction. 2008;37(8):799-801.

6. Wen KC, Yang CC, Wang PH. Primary fallopian tube leiomyoma managed by laparoscopy. J minim invasive gynecol. 2005;12(3):193. 